\title{
Article
}

\section{First-Year Healthcare Resource Utilization Costs of Five Major Cancers in Japan}

\author{
Tomone Watanabe ${ }^{1,2, * \mathbb{D}}$, Rei Goto ${ }^{3}$, Yoko Yamamoto ${ }^{1}$, Yuichi Ichinose ${ }^{1} \mathbb{D}$ and Takahiro Higashi ${ }^{1,2}$ \\ 1 Division of Health Services Research, National Cancer Center, Tokyo 104-0045, Japan; \\ yokyamam@ncc.go.jp (Y.Y.); yuichino@ncc.go.jp (Y.I.); thigashi@ncc.go.jp (T.H.) \\ 2 Department of Social Medicine, Graduate School of Medicine, University of Tokyo, Tokyo 113-8654, Japan \\ 3 Graduate School of Business Administration, Keio University, Yokohama 223-8526, Japan; \\ reigoto@kbs.keio.ac.jp \\ * Correspondence: tomonwat@ncc.go.jp; Tel.: +81-335-422-511 (ext. 1770); Fax: +81-355-652-322
}

Citation: Watanabe, T.; Goto, R.; Yamamoto, Y.; Ichinose, Y.; Higashi, T. First-Year Healthcare Resource Utilization Costs of Five Major Cancers in Japan. Int. J. Environ. Res. Public Health 2021, 18, 9447.

https://doi.org/10.3390/ijerph 18189447

Academic Editor: Paul B. Tchounwou

Received: 28 July 2021

Accepted: 4 September 2021

Published: 7 September 2021

Publisher's Note: MDPI stays neutral with regard to jurisdictional claims in published maps and institutional affiliations.

Copyright: (c) 2021 by the authors. Licensee MDPI, Basel, Switzerland. This article is an open access article distributed under the terms and conditions of the Creative Commons Attribution (CC BY) license (https:// creativecommons.org/licenses/by/ $4.0 /)$.

\begin{abstract}
Reports on the expenditure of cancer treatments per patient using comprehensive data remain unavailable in Japan. This study aimed to use Japan's cancer registry data and health service utilization data for evaluating the disease-specific, per-patient costs of five major cancersstomach, lung, colorectal, liver, and breast cancers. We used a database linking the 2017 data from a hospital-based cancer registry and the health service utilization data from the Diagnosis Procedure Combination survey. All patients who started their first treatment course at each hospital were included. The costs were calculated using the total volume of the health services provided and the unit fee information included in the data. We analyzed 304,698 patients. Lung cancer had the highest healthcare cost per-patient for the first year of diagnosis and the longest median hospitalization duration. Conversely, breast cancer showed the lowest cost and the shortest median hospitalization duration. However, in the first month after diagnosis, colorectal cancer showed the highest cost. Subsequently, the gaps between the costs of the five common cancers drastically diminished. The cancer type having the longest hospitalization duration had the highest overall healthcare resource utilization costs. This information is essential for care planning and research studies.
\end{abstract}

Keywords: healthcare costs; major cancers; Japan

\section{Introduction}

The burden of cancer is continuously increasing. In 2018, around 16.8 million patients were newly diagnosed with cancer worldwide, leading to 9.6 million deaths, which have been constantly rising each year [1]. Healthcare resource utilization costs for cancer is increasing sharply, especially in high-income countries. For instance, in the United States, the healthcare resource utilization costs for 17 cancers reached 124.57 billion USD in 2010 and is expected to increase by $39 \%$ over the next decade [2]. The rising costs present a huge challenge for policymakers with respect to adequate resource management, which incorporates a comprehensive evaluation of resources used [3,4].

Likewise, Japan has increased incidence rates, causing a rapid surge in health expenditures, and an estimated 40 billion JPY is spent annually on cancer care [5-7]. This increment is possibly attributable to an increase in the number of patients resulting from the country's high aging population, and technological advances producing more expensive tests and treatments into the market. To develop measures necessary for appropriate resource allocation, policymakers need accurate information on how the resources are used to treat major diseases. These data will aid in establishing evidence-based policymaking in order to address the prospect of healthcare expenditures that are robust to change.

However, in Japan, no studies have used comprehensive data to investigate and report the detailed expenditures per patient. Therefore, this study aimed to describe the disease-specific, per patient costs of five major cancers, namely, stomach, lung, colorectal, 
liver, and breast cancers, using the nationwide cancer registry data and health service utilization data in Japan. Cancer control in Japan has long focused on these five cancers, which have high incidence or mortality rates [5]. This study also sought to examine the patterns of resources used, such as hospitalization duration or the number of hospital visits, to provide policymakers the information of service utilization patterns necessary for planning healthcare systems.

\section{Materials and Methods}

\subsection{Data Sources}

We used a database that linked the data from a nationwide hospital-based cancer registry (HBCR) $[8,9]$ and health service utilization data from the Diagnosis Procedure Combination (DPC) survey. The HBCR is a compulsory cancer incidence reporting system for all designated cancer care hospitals and non-designated hospitals that play similar roles in their local communities. The HBCR data include the clinical and pathological stages, tumor-node-metastasis (TNM) classifications (UICC 7th edition), tumor location, and histopathology according to the International Classification of Diseases Oncology 3rd edition (ICD-O-3). Using the database, we identified patients diagnosed with the five aforementioned cancers (ICD-O morphology codes: C16, C18-20, C34, C50, and C22) and included them in the analyses. Meanwhile, the DPC survey data contain information on all health services provided. Unlike DRG based per case payment system, the DPC based payment is a grouping system used to determine the amount of per day health insurance reimbursement to hospitals [10]. Additionally, its survey data contain the equivalent data for fee-for-service claims that register individual diagnostic tests, images, and procedures as well as the pharmacy claims for the prescription drugs. They also include the dates and unit costs of the services based on the national fee-schedule. In Japan, the health services are reimbursed to the providers on a fee-for-service basis, and the national fee-schedule define the amount of reimbursement for all individual health services ranging from physicians' services to laboratory tests, imaging services, drugs as well as prescription drugs $[10,11]$. Each price is set to reflect the cost structure of the production of each health service. The amount of reimbursement under fee-for-service system is widely used as the proxy of costs, from both inpatient and outpatient settings [12]. The utilization data along with HBCR data collected at each hospital were submitted to National Cancer Center for data linkage. The selected time period for DPC data included all treatments performed for cancers diagnosed in 2017 (from 1st January to 31st December). In order to include all costs during a year from diagnosis, the DPC data from January 2017 to December 2018 were used for this study. The details of data collection process are described elsewhere [9].

\subsection{Statistical Analysis}

We calculated the average and median healthcare resource utilization (HCRU) costs related to cancer care, number of hospitalizations and outpatient visits, and hospitalization duration per patient during the first year after the diagnosis date. All patients who started their first treatment course at each hospital were included. The costs were calculated using the total volume of the health services provided and the unit fee information found in the data. Costs were calculated as fee-for-service in this analysis in order to present the resources used for each cancer. In other words, we added each unit cost for each service provided. The service fees represent the service costs, considering that the unit fee schedule is identified to reflect the resources used in Japanese average healthcare providers. The total cost for outpatient care and inpatient care within a year per patient was calculated. The total cost for each cancer was then stratified according to patients' age, examining the amount of costs incurred per age stratum. All analysis data were confined to the first 12 months after the diagnosis date. Thus, we excluded all data obtained beyond the period or the cases that did not have the diagnosis date. If the discharge date exceeded 365 days after the diagnosis date, we included the cost incurred until a year after the diagnosis date. 
The cost variation across the individual cases was analyzed using a multilevel mixed effects linear model, separating out the statistical variance of cancer care costs from the grand mean within the hospital and individual cluster for each cancer type.

All statistical data were analyzed using Stata version 14.2 (StataCorp LP, College Station, TX, USA). The institutional review board of the National Cancer Center in Japan approved our study protocol.

\section{Results}

The study analyzed 304,698 patients. Table 1 shows the patients' demographic information. For each cancer, the results are presented as patients' age and their clinical stage (I-IV).

Table 1. Patient demographics (2017).

\begin{tabular}{|c|c|c|c|c|c|c|c|c|c|c|}
\hline & \multicolumn{2}{|c|}{ Liver } & \multicolumn{2}{|c|}{ Stomach } & \multicolumn{2}{|c|}{ Colorectal } & \multicolumn{2}{|c|}{ Lung } & \multicolumn{2}{|c|}{ Breast } \\
\hline$n$ & \multicolumn{2}{|c|}{15,808} & \multicolumn{2}{|c|}{69,695} & \multicolumn{2}{|c|}{90,912} & \multicolumn{2}{|c|}{70,264} & \multicolumn{2}{|c|}{58,019} \\
\hline Mean age (SD) & \multicolumn{2}{|c|}{$72.7(10.2)$} & \multicolumn{2}{|c|}{$72.2(10.4)$} & \multicolumn{2}{|c|}{$70.2(11.5)$} & \multicolumn{2}{|c|}{$71.7(10.4)$} & \multicolumn{2}{|c|}{$60.6(14.1)$} \\
\hline \multicolumn{11}{|l|}{ Stage (\%) } \\
\hline 0 & - & & - & - & 23,086 & 25.4 & 156 & 0.2 & 7584 & 13.1 \\
\hline I & 7375 & 46.7 & 44,312 & 63.6 & 17,542 & 19.3 & 28,310 & 40.3 & 23,997 & 41.4 \\
\hline II & 4156 & 26.3 & 6292 & 9 & 17,737 & 19.5 & 5708 & 8.1 & 17,320 & 29.9 \\
\hline III & 2665 & 16.9 & 6935 & 10 & 17,905 & 19.7 & 11,753 & 16.7 & 5938 & 10.2 \\
\hline IV & 1274 & 8.1 & 11,205 & 16.1 & 13,540 & 14.9 & 23,173 & 33 & 2965 & 5.1 \\
\hline unknown & 338 & 2.1 & 951 & 1.4 & 1102 & 1.2 & 1164 & 1.7 & 215 & 0.4 \\
\hline \multicolumn{11}{|l|}{ Age group (\%) } \\
\hline $0-29$ & 17 & 0.1 & 66 & 0.1 & 138 & 0.2 & 50 & 0.1 & 219 & 0.4 \\
\hline $30-39$ & 49 & 0.3 & 497 & 0.7 & 862 & 1 & 312 & 0.4 & 2678 & 4.6 \\
\hline $40-49$ & 331 & 2.1 & 1785 & 2.6 & 4120 & 4.5 & 1681 & 2.4 & 12,939 & 22.3 \\
\hline $50-59$ & 1183 & 7.5 & 4919 & 7.1 & 9947 & 10.9 & 5268 & 7.5 & 11,685 & 20.1 \\
\hline $60-69$ & 3962 & 25.1 & 18,317 & 26.3 & 25,719 & 28.3 & 20,024 & 28.5 & 13,947 & 24 \\
\hline $70-79$ & 5886 & 37.2 & 26,431 & 37.9 & 30,353 & 33.4 & 27,856 & 39.6 & 10,780 & 18.6 \\
\hline $80-$ & 4380 & 27.7 & 17,680 & 25.4 & 19,773 & 21.8 & 15,073 & 21.5 & 5771 & 10 \\
\hline \multicolumn{11}{|c|}{ Types of treatment * } \\
\hline Surgery & 12,887 & 81.5 & 59,369 & 85.2 & 81,231 & 89.4 & 39,005 & 55.5 & 51,245 & 88.3 \\
\hline Chemotherapy & 7106 & 45 & 17,929 & 25.7 & 27,848 & 30.6 & 32,065 & 45.6 & 19,826 & 34.2 \\
\hline Radiation & 1199 & 7.6 & 3106 & 4.5 & 4507 & 5 & 16,746 & 23.8 & 21,262 & 36.6 \\
\hline
\end{tabular}

* Data does not add up to $100 \%$ due to duplication.

\subsection{Costs in the First Year of Diagnosis}

Table 2 summarizes the distribution of the first-year costs per patient for the five common cancers. Lung cancer obtained the highest median overall costs per patient (2,508,789 JPY), while breast cancer showed the lowest (1,559,274 JPY). According to clinical stage, stage III cancers exhibited the highest median inpatient costs, except for colorectal cancer for which the highest inpatient cost was for stage IV. Stage III cancers also showed the highest outpatient median costs, except for liver and colorectal cancers. According to age group, patients in their $60 \mathrm{~s}$ and $70 \mathrm{~s}$ had the highest cancer care costs for all cancers. However, unlike other cancers, more than $50 \%$ of breast cancer care costs were consumed by patients below 60 years old.

Figure 1 illustrates the trend of average monthly cancer care costs per patient. Except for the first month, the lung cancer costs were highest throughout the year, although the gap drastically diminished after 2 months from diagnosis. The costs for all cancers, excluding breast cancer, were highest at the first month after diagnosis, but on the second month, breast cancer showed the highest. Although breast cancer generally had the lowest cancer care costs up until the sixth month threshold, it leveled with the colorectal and gastric cancer costs thereafter. When stratified by age, the cost trend was fairly similar across patients aged 40-79 years. Meanwhile, the treatment cost for liver cancer was 
relatively higher in patients in their 30s, and that for colorectal cancer in the first month was conspicuously the highest in patients aged 80 or above (Figure 2).

Table 2. Mean healthcare resource utilization costs of the five major cancers within a year after diagnosis per-patient in Japan (upper row: median, lower row: mean, unit: Yen).

\begin{tabular}{|c|c|c|c|c|c|c|c|c|c|}
\hline & Unit & 0 & I & II & III & IV & Unknown & $\begin{array}{c}\text { All } \\
\text { Stages }\end{array}$ & $\begin{array}{c}\text { Total } \\
\text { (Outpatient } \\
+ \text { Inpatient) }\end{array}$ \\
\hline \multirow{4}{*}{$\begin{array}{c}\text { Liver } \\
(n=15,808)\end{array}$} & \multirow{2}{*}{ Outpatient } & & 300,931 & 329,004 & 219,278 & 87,479 & 78,362 & 287,589 & \multirow[b]{2}{*}{$2,078,843$} \\
\hline & & & 618,592 & 631,108 & 500,150 & 517,268 & 284,751 & 586,611 & \\
\hline & \multirow{2}{*}{ Inpatient } & & $1,452,499$ & $1,819,571$ & $2,159,867$ & $1,304,000$ & $1,113,121$ & $1,623,739$ & \multirow[t]{2}{*}{$2,671,490$} \\
\hline & & & $1,826,721$ & $2,284,767$ & $2,618,544$ & $1,855,085$ & $1,918,391$ & $2,084,879$ & \\
\hline \multirow{4}{*}{$\begin{array}{c}\text { Stomach } \\
(n=69,695)\end{array}$} & \multirow{2}{*}{ Outpatient } & & 185,434 & 372,081 & 569,867 & 364,153 & 62,096 & 214,528 & \multirow[b]{2}{*}{$1,839,530$} \\
\hline & & & 292,830 & 521,520 & 790,280 & $1,071,880$ & 320,411 & 488,600 & \\
\hline & \multirow{2}{*}{ Inpatient } & & 918,689 & $2,011,916$ & $2,290,073$ & $1,876,265$ & 916,390 & $1,509,190$ & \multirow[t]{2}{*}{$2,421,138$} \\
\hline & & & $1,654,133$ & $2,487,039$ & $2,754,346$ & $2,253,904$ & $1,456,846$ & $1,932,538$ & \\
\hline \multirow{4}{*}{$\begin{array}{l}\text { Colorectal } \\
(n=90,912)\end{array}$} & \multirow{2}{*}{ Outpatient } & 93,885 & 204,391 & 242,377 & 702,285 & 921,884 & 40,656 & 222,396 & \multirow[b]{2}{*}{$2,058,540$} \\
\hline & & 230,635 & 323,130 & 441,633 & 852,293 & $1,691,874$ & 408,588 & 631,870 & \\
\hline & \multirow{2}{*}{ Inpatient } & 371,859 & $1,632,299$ & $1,872,095$ & $2,009,314$ & $2,345,584$ & $1,141,618$ & $1,630,101$ & \multirow[t]{2}{*}{$2,713,002$} \\
\hline & & 728,364 & $1,849,647$ & $2,361,973$ & $3,198,947$ & $2,875,019$ & $1,668,914$ & $2,081,132$ & \\
\hline \multirow{4}{*}{$\begin{array}{c}\text { Lung } \\
(n=70,264)\end{array}$} & \multirow{2}{*}{ Outpatient } & 155,190 & 255,066 & 391,025 & 537,181 & 383,286 & 82,491 & 317,223 & \multirow[b]{2}{*}{$2,508,789$} \\
\hline & & 210,582 & 414,857 & 683,542 & $1,231,550$ & $1,681,510$ & 401,530 & 990,358 & \\
\hline & \multirow{2}{*}{ Inpatient } & $1,700,838$ & $1,899,493$ & $2,432,563$ & $2,518,769$ & $1,910,023$ & 937,621 & $1,979,050$ & \multirow{2}{*}{$3,366,480$} \\
\hline & & $1,846,962$ & $2,069,106$ & $2,785,343$ & $2,849,596$ & $2,460,904$ & $1,438,782$ & $2,376,122$ & \\
\hline \multirow{4}{*}{$\begin{array}{c}\text { Breast } \\
(n=58,019)\end{array}$} & \multirow{2}{*}{ Outpatient } & 233,410 & 590,118 & 809,373 & $1,367,112$ & $1,313,672$ & 265,459 & 647,501 & \multirow[b]{2}{*}{$1,559,274$} \\
\hline & & 386,271 & 728,104 & $1,076,681$ & $1,537,909$ & $2,239,234$ & 800,032 & 947,850 & \\
\hline & \multirow{2}{*}{ Inpatient } & 726,813 & 744,886 & 928,522 & $1,085,048$ & 809,365 & 376,633 & 820,950 & \multirow{2}{*}{$2,012,925$} \\
\hline & & 919,149 & 970,355 & $1,133,881$ & $1,353,685$ & $1,253,190$ & 676,353 & $1,065,075$ & \\
\hline
\end{tabular}

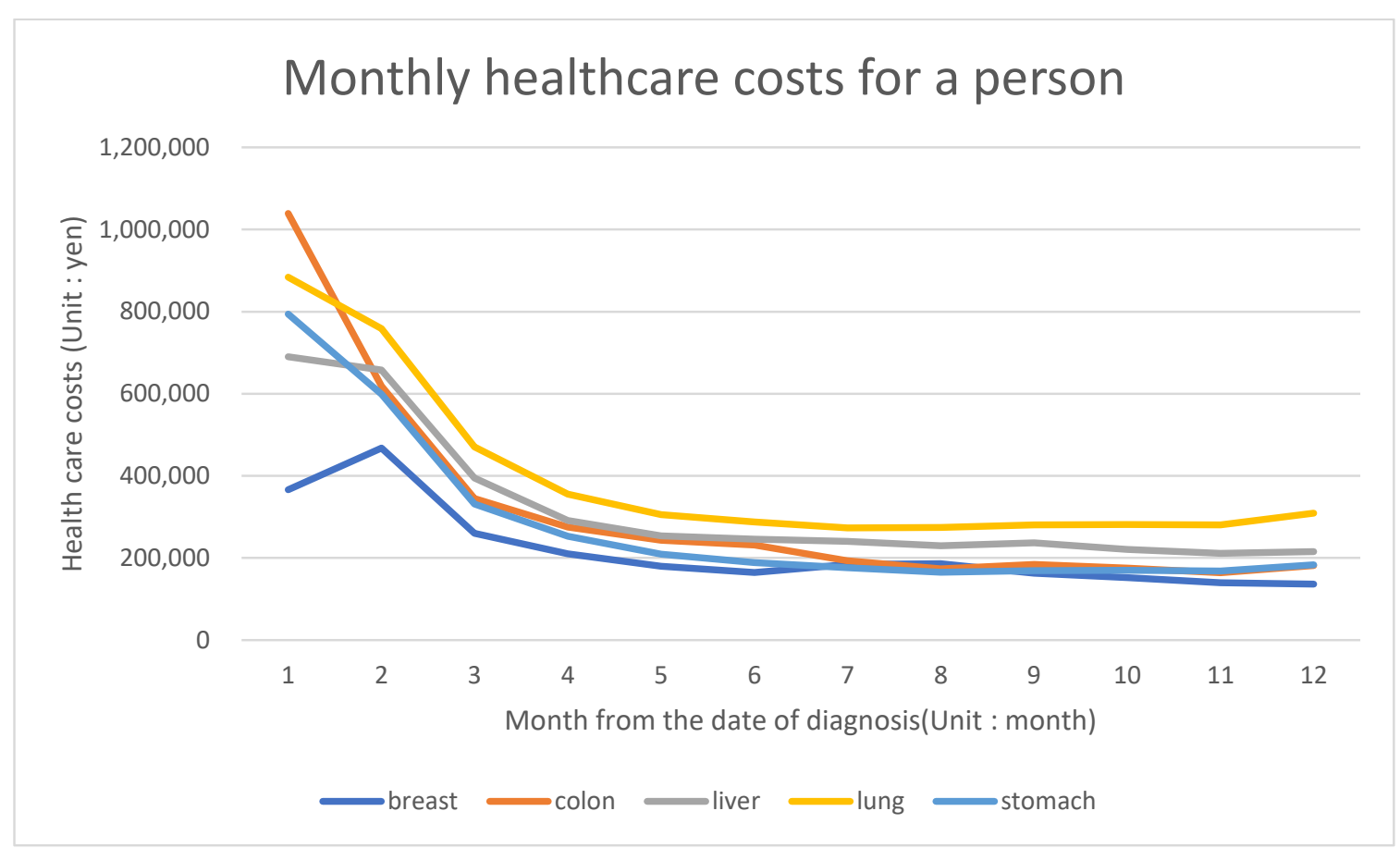

Figure 1. Monthly healthcare cost of each of the five major cancers per-patient. 


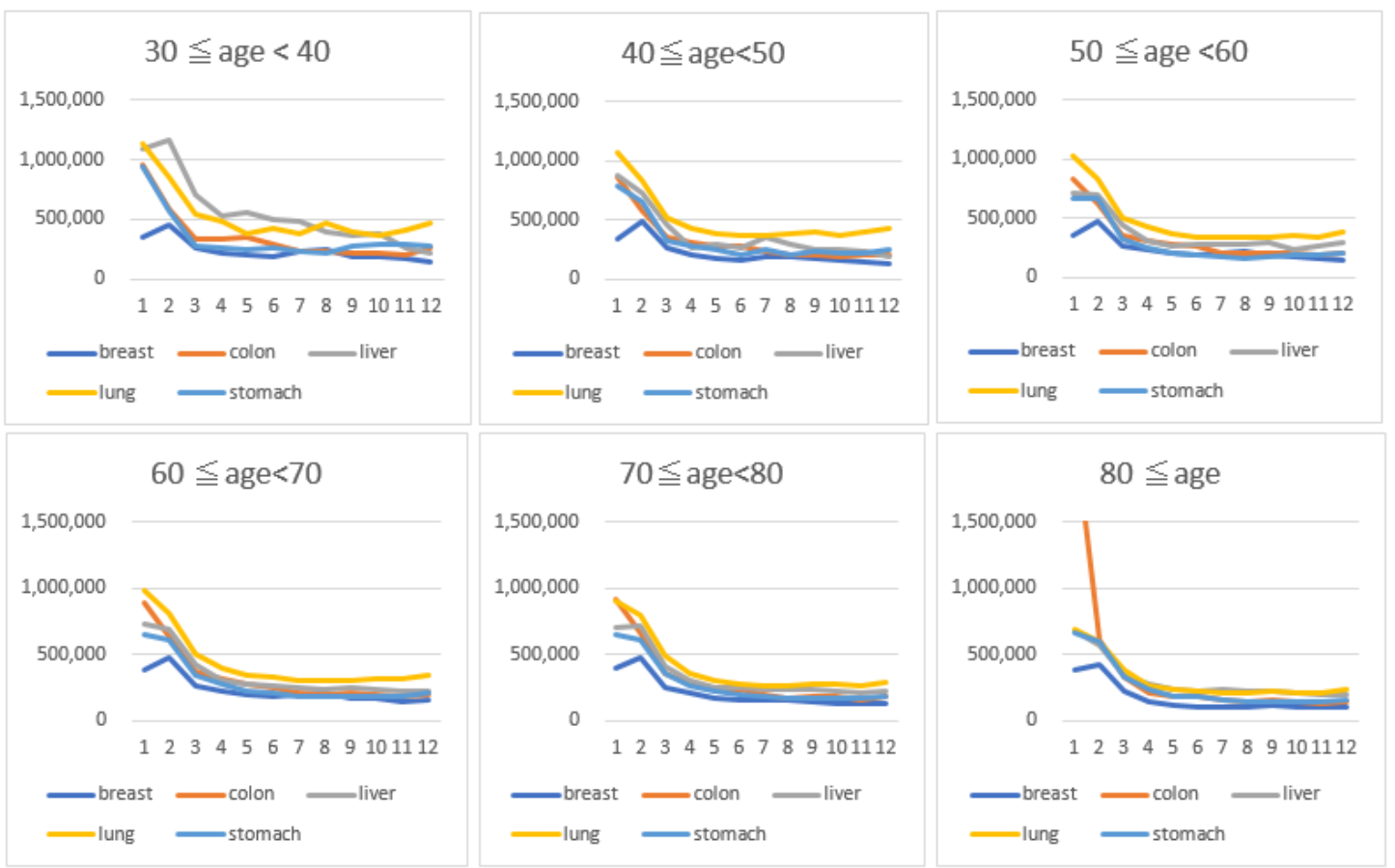

Figure 2. Monthly healthcare cost of each of the five major cancers per-patient stratified by age.

\subsection{Number of Outpatient Visits in a Year}

Table 3 presents the trend for the number of outpatient visits and hospitalization. Breast cancer showed the highest median number of outpatient visits (25 visits), while other cancers obtained less than 15 visits. In addition, the median number of hospitalizations was within the range of 1-3. Together with other factors, outpatient visits impacted the total number of hospital visits than the number of hospitalizations. For most cancers, patients in stage II or stage III visit hospitals most frequently.

Table 3. Annual number of outpatient visits and hospitalization per-patient (upper: median, lower: mean).

\begin{tabular}{|c|c|c|c|c|c|c|c|c|}
\hline & Unit & 0 & $\mathbf{I}$ & II & III & IV & Unknown & Total \\
\hline \multirow{4}{*}{ Liver } & \multirow{2}{*}{ Outpatient } & \multirow{2}{*}{-} & 12 & 13 & 9 & 3 & 4 & 12 \\
\hline & & & 14 & 14 & 11 & 8 & 7 & 13 \\
\hline & \multirow{2}{*}{ Inpatient } & \multirow{2}{*}{-} & 2 & 2 & 2 & 1 & 1 & 2 \\
\hline & & & 2 & 2 & 2 & 2 & 2 & 2 \\
\hline \multirow{4}{*}{ Stomach } & \multirow{2}{*}{ Outpatient } & \multirow{2}{*}{-} & 10 & 15 & 18 & 12 & 3 & 11 \\
\hline & & & 12 & 16 & 19 & 15 & 8 & 13 \\
\hline & \multirow{2}{*}{ Inpatient } & \multirow{2}{*}{-} & 1 & 1 & 2 & 2 & 1 & 1 \\
\hline & & & 2 & 2 & 2 & 3 & 2 & 2 \\
\hline \multirow{4}{*}{ Colorectal } & \multirow{2}{*}{ Outpatient } & 5 & 11 & 12 & 17 & 19 & 2 & 11 \\
\hline & & 8 & 13 & 14 & 18 & 19 & 8 & 14 \\
\hline & \multirow{2}{*}{ Inpatient } & 1 & 1 & 1 & 2 & 2 & 1 & 1 \\
\hline & & 1 & 2 & 2 & 2 & 3 & 2 & 2 \\
\hline \multirow{4}{*}{ Lung } & \multirow{2}{*}{ Outpatient } & 8 & 12 & 17 & 19 & 11 & 4 & 13 \\
\hline & & 10 & 14 & 19 & 21 & 15 & 9 & 15 \\
\hline & \multirow{2}{*}{ Inpatient } & 1 & 1 & 2 & 3 & 2 & 1 & 2 \\
\hline & & 1 & 2 & 3 & 3 & 3 & 2 & 2 \\
\hline \multirow{4}{*}{ Breast } & \multirow{2}{*}{ Outpatient } & 16 & 25 & 27 & 37 & 22 & 10 & 25 \\
\hline & & 21 & 26 & 30 & 37 & 24 & 16 & 27 \\
\hline & \multirow{2}{*}{ Inpatient } & 1 & 1 & 1 & 1 & 1 & 1 & 1 \\
\hline & & 1 & 1 & 2 & 2 & 1 & 1 & 1 \\
\hline
\end{tabular}




\subsection{Average Hospitalization Duration}

Table 4 shows the distribution of hospitalization duration. The median hospitalization duration was longest in lung cancer (22 days) and shortest in breast cancer (9 days). Stages III and IV marked the longest hospitalization duration for all cancers.

Table 4. Hospitalization duration per-patient (upper: median, lower: mean).

\begin{tabular}{cccccccc}
\hline \multirow{2}{*}{ Liver } & 0 & I & II & III & IV & Unknown & Total \\
& - & 17 & 23 & 34 & 28 & 20 & 21 \\
\multirow{2}{*}{ Stomach } & - & 12 & 32 & 42 & 36 & 32 & 31 \\
& & 19 & 23 & 29 & 34 & 22 & 16 \\
\multirow{2}{*}{ Colorectal } & 4 & 16 & 22 & 24 & 34 & 23 & 18 \\
& 9 & 23 & 31 & 33 & 43 & 33 & 26 \\
\multirow{2}{*}{ Lung } & 10 & 12 & 28 & 46 & 37 & 19 & 22 \\
& 14 & 18 & 39 & 53 & 48 & 31 & 36 \\
\multirow{2}{*}{ Breast } & 8 & 8 & 10 & 13 & 10 & 6 & 9 \\
& 10 & 11 & 14 & 19 & 23 & 13 & 13 \\
\hline
\end{tabular}

\subsection{Statistical Variance of Cancer Care Costs}

The individual monthly cancer care costs from the diagnosis were modeled as fixed parameters, and the facilities and individual patients as random parameters (Table 5). We hypothesized that the patient-defined statistical variance is always greater than the facilitydefined variance. The standard deviation (SD) of hospital level cancer care costs from the grand mean was smaller than that of individual level cancer care costs from the hospital mean, except for breast cancer. Colorectal cancer had the greatest SD of hospital level cancer care costs from the grand mean, while lung cancer showed the smallest. Colorectal cancer also exhibited the greatest SD of individual-level cancer care costs from the hospital mean, while breast cancer obtained the smallest.

Table 5. Statistical variance of cancer care cost using mixed method.

\begin{tabular}{cccccc}
\hline & Liver & Stomach & Colorectal & Lung & Breast \\
\hline Grand mean & $2,605,715$ & $2,493,774$ & $2,823,430$ & $3,311,205$ & $2,118,407$ \\
\hline Facility level (SD) & 904,880 & $2,589,735$ & $4,077,456$ & 485,880 & $2,015,123$ \\
\hline Individual level (SD) & $2,398,249$ & $39,439,543$ & $41,150,914$ & $2,513,716$ & $1,609,051$ \\
\hline
\end{tabular}

\section{Discussion}

In summary, our study revealed that the treatment costs vary across major cancers in Japan. Lung cancer obtained the highest overall costs for the first year after diagnosis and the longest median hospitalization duration (22 days). In contrast, breast cancer showed the lowest costs and the shortest hospitalization duration. In the first month after diagnosis, colorectal cancer showed the highest costs. Nevertheless, the gaps between the costs among these five cancers drastically diminished in the following months. Furthermore, the age-stratified cancer care costs in the first year of diagnosis were relatively the same across the age strata, except for patients in their 30s and those aged 80 years and above. Additionally, patient defined statistical variance was always greater than facility defined statistical variance, indicating that the costs were determined by the care provided for each patient.

The overall trend of costs for the first year agrees with those in other studies conducted in the US and elsewhere [2,13-15]. Colorectal cancer is reportedly the most expensive in the initial treatment phase. The initial and terminal phase costs for colorectal cancer were previously discussed $[2,16]$. One of the greatest contributors to this phenomenon 
is inpatient costs such as the personalized use of drugs and more tests [17]. In Japan, although the costs incurred at the first month of diagnosis for colorectal cancer is similar to those for lung cancer, the costs for lung cancer are always slightly ahead of the curve. Although the incidence of colorectal cancer outnumbers that of lung cancer, lung cancer mortality remains to be higher [18]. As stage information as well as types of treatment in Table 1 shows, more patients with lung cancers are diagnosed at the later stage [19], possibly leading to higher costs. Japanese studies suggest less expensive ways of treating colorectal cancer, such as the use of KRAS test before a particular chemotherapy as opposed to KRAS preselection test; however, further studies are needed to ascertain its effect $[17,20]$. Moreover, greater hospital level statistical variances of cancer care costs, especially for colon cancer, may implicate practice variations across hospitals.

A longer hospitalization duration is associated with higher healthcare resource utilization costs [21]. Although Japan is well known for its relatively long hospitalization duration [22], no single solution can solve this long standing issue, considering that various aspects of the disease and social characteristics determine the hospitalization duration [23]. The nation's aging population continues to rise; thus, the high cancer care costs incurred by prolonged hospitalization duration are expected to increase further. In addition, focusing on a holistic approach to care, such as promoting a smooth transition to home-based care, augmenting social resources and support, and providing team-based management of comorbidity, has become increasingly important to reduce the overall costs.

However, our study has several limitations. First, we failed to capture the details of care provided at other hospitals if a patient moves from one hospital to another, although such cases are uncommon, as revealed by other studies [24]. This lapse could still potentially underestimate the amount of medical care cost per-patient. Although cancer treatment costs involve not only medical expenses but also travel expenses and opportunity expenses, which are a forgone value of time for patients and their family, we only reported the medical care costs based on the national fee schedule, thereby potentially limiting the application of the findings. Nevertheless, the baseline raw data were well represented in our study and considered important, especially in determining the overall cancer care costs. In 2019, Japan introduced an official health technology assessment system, which suggests that conducting more economic evaluations of cancer care are necessary. In conducting such economic evaluations, individual medical care costs must be identified. Finally, we analyzed the absolute cancer care costs, not the incremental cost matched with those costs in patients without cancer. If the policy target is the extensive resource allocation to cancer care, comparison with the costs for noncancer diseases is required.

\section{Conclusions}

Using the nationwide database, we successfully described the healthcare resource utilization costs of five major cancers (stomach, lung, colorectal, liver, and breast cancers) and their trend after diagnosis. The cancer that had the longest hospitalization duration had the highest overall costs. The findings of this study provide information necessary for care planning and research studies. Such data should be monitored regularly, and the policymakers should contain the costs as efficient as possible.

Author Contributions: Conceptualization, T.W., R.G. and T.H.; Methodology, T.W. and T.H.; Validation, Y.I. and Y.Y.; Formal Analysis, T.W. and Y.Y.; Investigation, T.W. and Y.Y.; Data Curation, T.W. and Y.Y.; Writing-Original Draft Preparation, T.W.; Writing-Review \& Editing, R.G., T.H.; Visualization, T.W.; Supervision, T.H.; Project Administration, T.W.; Funding Acquisition, T.H. All authors have read and agreed to the published version of the manuscript.

Funding: This work was funded by a grant from National Cancer Center, Japan.

Institutional Review Board Statement: The institutional review board of the National Cancer Center in Japan approved the protocol of this study.

Informed Consent Statement: Consent for publication was obtained through information disclosure and optout. 
Data Availability Statement: The datasets generated during and/or analyzed during the current study are available from the corresponding author on request.

Conflicts of Interest: The authors declare no conflict of interest.

\section{References}

1. Fitzmaurice, C.; Abate, D.; Abbasi, N.; Abbastabar, H.; Abd-Allah, F.; Abdel-Rahman, O.; Abdelalim, A.; Abdoli, A.; Abdollahpour, I.; Abdulle, A.S.M.; et al. Global, Regional, and National Cancer Incidence, Mortality, Years of Life Lost, Years Lived with Disability, and Disability-Adjusted Life-Years for 29 Cancer Groups, 1990 to 2017: A Systematic Analysis for the Global Burden of Disease Study. JAMA Oncol. 2019, 5, 1749-1768. [PubMed]

2. Mariotto, A.B.; Yabroff, K.R.; Shao, Y.; Feuer, E.J.; Brown, M.L. Projections of the cost of cancer care in the United States: 2010-2020. J. Natl. Cancer Inst. 2011, 103, 117-128. [CrossRef]

3. Sullivan, R.; Peppercorn, J.; Sikora, K.; Zalberg, J.; Meropol, N.J.; Amir, E.; Khayat, D.; Boyle, P.; Autier, P.; Tannock, 1.F.; et al. Delivering affordable cancer care in high-income countries. Lancet Oncol. 2011, 12, 933-980. [CrossRef]

4. Aggarwal, A.; Ginsburg, O.; Fojo, T. Cancer economics, policy and politics: What informs the debate? Perspectives from the EU, Canada and US. J. Cancer Policy 2014, 2, 1-11. [CrossRef]

5. National Cancer Center, Cancer Statistics in Japan. 2021. Available online: https://ganjoho.jp/public/qa_links/report/statistics/ pdf/cancer_statistics_2021_data_E.pdf (accessed on 28 August 2021).

6. International Agency for Research on Cancer, Japan. Available online: https://gco.iarc.fr/today/data/factsheets/populations/ 392-japan-fact-sheets.pdf (accessed on 28 August 2021).

7. OECD. "Health Expenditure and Financing: Health Expenditure Indicators", OECD Health Statistics (Database). 2021. Available online: https: / / doi.org/10.1787/data-00349-en (accessed on 28 August 2021).

8. Higashi, T.; Nakamura, F.; Shibata, A.; Emori, Y.; Nishimoto, H. The national database of hospital-based cancer registries: A nationwide infrastructure to support evidence-based cancer care and cancer control policy in Japan. Jpn. J. Clin. Oncol. 2014, 44, 2-8. [CrossRef] [PubMed]

9. Iwamoto, M.; Nakamura, F.; Higashi, T. Monitoring and evaluating the quality of cancer care in Japan using administrative claims data. Cancer Sci. 2016, 107, 68-75. [CrossRef] [PubMed]

10. Yasunaga, H.; Ide, H.; Imamura, T.; Ohe, K. Impact of the Japanese Diagnosis Procedure Combination-based Payment System on cardiovascular medicine-related costs. Int. Heart J. 2005, 46, 855-866. [CrossRef] [PubMed]

11. Japan Health Policy Now. The Medical Service Fee System. Available online: https://japanhpn.org/en/section-7-2/ (accessed on 28 August 2021).

12. Shiroiwa, T.; Fukuda, T.; Ikeda, S.; Takura, T.; Moriwaki, K. Development of an official guideline for the economic evaluation of drugs/medical devices in Japan. Value Health 2017, 20, 372-378. [CrossRef]

13. Luengo-Fernandez, R.; Leal, J.; Gray, A.; Sullivan, R. Economic burden of cancer across the European Union: A population-based cost analysis. Lancet Oncol. 2013, 14, 1165-1174. [CrossRef]

14. Blakely, T.; Atkinson, J.; Kvizhinadze, G.; Wilson, N.; Davies, A.; Clarke, P. Patterns of cancer care costs in a country with detailed individual data. Med. Care 2015, 53, 302-309. [CrossRef] [PubMed]

15. Goldsbury, D.E.; Yap, S.; Weber, M.F.; Veerman, L.; Rankin, N.; Banks, E.; Kanfell, K.; O'Connell, D.L. Health services costs for cancer care in Australia: Estimates from the 45 and up study. PLoS ONE 2018, 13, e0201552. [CrossRef] [PubMed]

16. Damm, O.; Hodek, J.M.; Greiner, W. Methodological standards for cost-of-illness studies using breast cancer, prostate cancer and colon cancer as an example. Z. Evid. Fortbild. Qual. Gesundhwes. 2009, 103, 305-316. [CrossRef] [PubMed]

17. Kriza, C.; Emmert, M.; Wahlster, P.; Niederländer, C.; Kolominsky-Rabas, P. Cost of illness in colorectal cancer: An international review. Pharmacoeconomics 2013, 31, 577-588. [CrossRef]

18. National Cancer Center. Cancer Mortality Rate. 2018. Available online: https://ganjoho.jp/reg_stat/statistics/stat/summary. html (accessed on 1 July 2021).

19. Ellis, P.M.; Vandermeer, R. Delays in the diagnosis of lung cancer. J. Thorac. Dis. 2011, 3, 183-188.

20. Yajima, S.; Shimizu, H.; Sakamaki, H.; Ikeda, S.; Ikegami, N.; Murayama, J.I. Real-world cost analysis of chemotherapy for colorectal cancer in Japan: Detailed costs of various regimens during the entire course of chemotherapy. BMC Health Serv. Res. 2016, 16, 2. [CrossRef] [PubMed]

21. Fine, M.J.; Pratt, H.M.; Obrosky, D.S.; Lave, J.R.; Mclntosh, L.J.; Singer, E.D.; Coley, C.M.; Kapoor, W.N. Relation between length of hospital stay and costs of care for patients with community-acquired pneumonia. Am. J. Med. 2000, 109, 378-385. [CrossRef]

22. OECD. Average Length of Stay in Hospitals. Available online: https://www.oecd-ilibrary.org/sites/0d8bb30a-en/index.html? itemId=/content/component/0d8bb30aen\#: :text=In\%202017\%2C\%20the\%20aveage\%20length,over\%2016\%20days\%20per\% 20patient (accessed on 1 July 2021).

23. Muramatsu, N.; Liang, J. Hospital length of stay in the United States and Japan: A case study of myocardial infarction patients. Int. J. Health Serv. 1999, 29, 189-209. [CrossRef] [PubMed]

24. Watanabe, T.; Mikami, M.; Katabuchi, H.; Kato, S.; Kaneuchi, M.; Takahashi, M.; Nakai, H.; Nagase, S.; Niikura, H.; Mandai, M.; et al. Quality indicators for cervical cancer care in Japan. J. Gynecol. Oncol. 2018, 29, e83. [CrossRef] [PubMed] 